\title{
NOTAS
}

\section{Nuevas notas acerca de los arabismos de la documentación bajo-latina leonesa}

\author{
Further remarks on arabic loanwords \\ in low latin materials from Leon
}

Federico Corriente

Universidad de Zaragoza

RESUMEN: Examen de arabismos y voces afines, con propuesta de correcciones a étimos anteriormente propuestos para ese material, en el marco de la investigación más reciente acerca del impacto del árabe estándar y andalusí en las lenguas iberorromances.

Palabras clave: iberorromance, arabismos, árabe estándar, árabe andalusí.

ABSTRACT: A survey of Arabic and related loanwords and occasional corrections to previous etima proposed for them, in relation with recent research on the impact of Standard and Andalusi Arabic on the lexica of Ibero-Romance languages.

Keywords: Ibero-Romance languages, Arabic loanwords, Standard Arabic, Andalusi Arabic.

Recientemente hemos recibido la grata sorpresa del envío por su autor, Maurilio Pérez, de su importante Lexicon Latinitatis Medii Aevii Regni Legionis (s. VIII-1230) Imperfectum que, a pesar de la ambigua apariencia de este último adjetivo, nos ha parecido la más completa obra de su clase hasta la fecha, al menos desde el punto de vista etimológico que más particularmente nos concierne, ya que, a diferencia de otras muy notorias, alguna de las cuales hemos enjuiciado en fechas recientes ${ }^{1}$, ha prestado la debida atención no sólo a los

1 Vgr., nuestras «Apostillas etimológicas a las voces orientales del Diccionario de la prosa castellana de Alfonso X de Kasten \& Nitti», en Revista de Filología Española XC, 1, 2010, 
materiales de origen latino, germánico o prerromano, sino también a la no despreciable aportación árabe al léxico de las lenguas iberorromances durante la Edad Media.

Nos ha parecido manera correcta de agradecer al compañero no sólo la amabilidad de su pronto envío, sino del frecuente uso que hace de nuestros materiales etimológicos, siempre correctamente atribuidos a no menos de diez trabajos, efectuar una inmediata y sosegada lectura de su obra, con la intención de responder a su mérito con un registro de observaciones que suscita, en general, adiciones de alguna información que pudiese contribuir a resolver alguno de los enigmas que las etimologías suelen plantear, sugerencias de alguna posibilidad, más o menos probable, de interpretar la escasa información disponible, alguna palinodia requerida por sus datos, o incluso alguna discrepancia de opinión, siempre inevitable, ya que el romanista y el orientalista normal y necesariamente miran las cosas a través de cristales de color algo distinto, siendo siempre preferible que las cosas se observen desde varios puntos de vista, y no sólo desde uno.

Hacemos, pues, la relación de los pasajes que han merecido nuestro comentario:

pág. 11: «adil(e) ... Sust. de etimología muy dudosa, pudiendo ser una voz prerrom.». De la ausencia de comentario se deduce que el autor descarta el origen árabe, ya propuesto por Machado para el portugués y escasamente modificado por Dolores Oliver ${ }^{2}$, en los términos recogidos en nuestro A Dictionary of Arabic and Allied Loanwords Spanish, Portuguese, Catalan,Galician and Kindred Dialects ${ }^{3}$. Teniendo en cuenta que nuestra propuesta de un étimo ár. and. alanádir 'las eras' requeriría una caída de /n/ y /l/ intervocálicas, regular en el ámbito galaico-portugués, pero no en el leonés, y que el desplazamiento acentual que explicamos por contaminación con el sufijo romance $\{-I ́ L\}$ es tan necesario para esta hipótesis como para la de Machado, el ár. Sātil, nos sentimos ahora inclinados a devolver la razón al etimólogo luso, a la vista asimismo de que dicha voz no sólo significa 'desadornado', sino también, muy particularmente en neoárabe, 'desocupado; sin trabajo', como es el caso de un terreno

págs. 47-106, en las que, una vez más, hemos debido insistir en criticar la lamentable frecuencia con que grandes especialistas en lexicología romance hacen bueno en este terreno, con respecto a las voces «exóticas», el viejo adagio medieval de «graece, non legitur». No muy distinto son los casos a los que nos referimos en nuestros artículos «Los arabismos de La Lozana Andaluza», en Estudis Romànics, XXXII, 2010, págs. 51-72 y «Los arabismos del léxico hispánico primitivo», en Revista de Filología Española LXIV, 1, 2004, págs. 67-93, por no hablar de observaciones similares esparcidas en otros rincones de nuestra producción en este campo.

${ }^{2}$ En «Los arabismos en la documentación del Reino de León (siglos IX-XII) y Glosario de arabismos», Orígenes de las lenguas romances en el Reino de León. Siglos IX-XII, II, León, 2004, págs. 99-291, esp. 160-161.

${ }^{3}$ Leiden, Brill, 2008; en adelante abreviado como DAAL. 
baldío o en barbecho, y lo confirma para el andalusí nuestro A Dictionary of Andalusi Arabic ${ }^{4}$, al tiempo que ese tipo de desplazamiento de acento, por metanálisis de un sufijo romance es un fenómeno conocido hace tiempo y descrito en DAAL, pág. lix, con ejemplos como el cat. atifell 'herramienta' < ár. and. atífil, y el mismo port. adil que allí ya se cita, entre otros. Por lo demás, la presencia de arabismos en el léxico agropecuario de la región está bien establecida hace tiempo (cf. ademna, aceña, acémila, albar, almenara, azud, dula, naranjo, zumaque, etc.) y no puede extrañar, dada la importancia de la inmigración de los emprendedores mozárabes que tanto desarrollaron la primitiva economía del reino astur-leonés.

pág. 33: ALMANCINA, ALMAZINA: «palabra de significado y étimo desconocidos», según decíamos nosotros mismos en DAAL, pág. 142, pero quizás no lo sea tanto, ahora que nuestro compañero nos proporciona una segunda cita, con la que deja de ser un hápax. Teniendo en cuenta lo extraño que resulta que la frecuente voz ár. manzil o manzalah 'asentamiento' no se haya reflejado entre los arabismos del iberorromance, aunque sí frecuentemente en la toponi$\operatorname{mia}^{5}$, y que esta acepción se ajusta razonablemente a los dos casos que conocemos en la documentación leonesa, es muy probable sea ése su étimo que, por otra parte, nos puede explicar también la extraña acepción de manzana (de casas) en castellano.

pág. 42: andamio: «lugar de paso, sendero». El autor se adhiere a la hipótesis de un étimo exclusivamente romance, basado en el verbo andar, con una sufijación extraña, pero documentada por Coromines, en los términos citados en DAAL, pág. 178, pero el port. andaime/o, con una vocalización que así no se explicaría, y la acepción dominante, 'armazón para construcciones', nos parecen asegurar la contaminación por dicho verbo romance del ár. and. adda Sáyim 'soportes' allí propugnada, apoyada además por el sinónimo homorrizo adema, q.v. en DAAL, pág. 31.

pág. 43: ANIGMA: «palabra desconocida [...] parte del ajuar de la casa». Teniendo en cuenta que se la menciona justo antes de una arrotoma (= redoma, v. pág. 78), nos parece muy probable se trate de otro tipo de vasija, neoár. nimah, de origen persa, que llamó la atención de Simonet $^{6}$ y él quiso derivar del lat. nimbus, pero v. DAA, pág. 545. La extraña ortografía ha podido resultar de una contaminación con (a)enigma.

\footnotetext{
${ }^{4}$ Leiden, Brill, 1997, pág. 357; en adelante abreviado como DAA.

${ }^{5}$ V. nuestro A gramatical sketch of the Spanish Arabic dialect bundle, Madrid, Instituto Hispano-Árabe de Cultura, 1977, pág. 41, n. 42, con ejemplos repartidos por toda la geografía peninsular y todos, incidentalmente, con disimilación de la primera nasal como en ALMAZINA.

${ }^{6}$ En su Glosario de voces ibéricas y latinas usadas entre los mozárabes, Madrid, Fortanet, 1888, pág. 400 .
} 
pág. 44: annemates: «sartal de perlas», pero el autor tiene razonables dudas acerca de que los etimólogos hayamos acertado en esta palabra, y nos ha hecho reflexionar sobre ella más allá de lo que expresábamos en DAAL, pág. 182 (s.v. annamath), pues parece evidente que en este documento leonés, a diferencia de otros, no puede tratarse de un tapiz de fieltro ni cosa parecida, ya que se habla de una corona «de annemates cum olouitreo aurea». Un examen de los casos en que aparece olouitreus en pág. 523 nos sugiere que se trate de una variedad de esmalte, muy característico de las artes menores islámicas, y que la voz original fuese un hápax *alminat, un esperable pl. neoár. del conocido iranismo neoár. miñ $\bar{a}$ 'esmalte', tal vez contaminado gráficamente por la otra voz más documentada.

pág. 44: annosca: es un término que el autor declara dudoso, no convenciéndole un étimo germánico nusca 'fíbula' que, efectivamente, encaja mal, al menos en la primera aparición citada, «Sella argentea I, uiarce argentea cum suas annoscas, mudas de mensa X, façales III». Sugerimos leer «VI arce argentea(e)» y entender 'seis cajas de plata' y proponer, aunque muy dubitativamente, la lectura *aluoscas, donde, como el precedente annemates, un bilingüe conocedor de la asimilación del artículo árabe habría pseudocorregido la /1/ ante $/ \mathrm{n} /$, fácilmente confundible con $<\mathrm{u}>$, lo que nos dejaría el ár. wasq(ah) 'carga', documentado en andalusí (DAA, pág. 564), o sea, que se trataría de cajas con su contenido precioso, monedas o joyas.

pág. 95: barrera y barrial, derivados de barro, son afectados por el descubrimiento que hicimos recientemente en un artículo aún inédito, de que esta voz no es prerromana, sino que comparte el étimo árabe de barrio, más exactamente la voz árabe de la que deriva el gentilicio que lo es, es decir, el sustantivo barr 'tierra'. Decimos en dicho artículo que embarrancar 'fracasar' puede reflejar el ár. barr 'tierra', a través del lenguaje marinero, pues una reflexión sobre el hecho de que cuando una nave embarranca no es porque se meta en un barranco, sino porque encalla o toca tierra (cf. el inglés to run aground), es decir, el limo que abunda en las orillas, sobre todo de los ríos, permite resolver el enigma etimológico del estándar barro, al que Coromines dedica típicamente varias columnas, para concluir afirmando que parece «prehispánico», lo que no deja de ser paradójico, tras haber resuelto él mismo brillantemente el caso emparentado del arabismo barrio (v. DAAL, pág. 61, s. v. alb/varrã).

pág. 243: DESCARLIN: acierta el autor al analizar esta voz como d' escarlin, pero tal vez no al identificar esta tela con la escarlata, ya que el escarín, ortografía mejor de Mio Cid, que venimos discutiendo desde un artículo publicado hace tres décadas ${ }^{7}$, no parece ser lo mismo que aquélla, como se indica allí y

\footnotetext{
${ }^{7}$ «Los romancismos del Vocabulista in arabico: addenda et corrigenda», en Vox Romanica, XXXIX, 1980, págs. 194-210, esp. 208, a lo que hay que añadir la aparición del mismo término
} 
en la entrada del DAA, pág. 19, lo que no habría impedido esa contaminación fonética en la última sílaba.

pág. 296: falifo «piel de cordero usada para forros»: la argumentación y documentación del autor, sobre todo la cita del marroquí hniff, eslabón ár. occidental que echábamos de menos en DAAL, pág. 293, obligan a corregir este artículo allí, devolviendo la razón que ya tuvieran a Dozy \& Engelmann y sus seguidores, a favor del étimo ár. antiguo haniff 'tejido basto de lino'. No es, desde luego y por consiguiente, bereber, como creían aquellos autores y aún afirma el excelente diccionario de Premare $^{8}$.

pág. 297: farouus «desconocemos la etimología y la acepción de este término». Al añadirse en el contexto «de lino setato», se debe presumir sea una prenda de vestir y cabría imaginar una mala lectura de *farem(e)s, o sea, los conocidos alfaremes, según DAAL, pág. 105, ya descritos, como última acepción por Dozy 9 . Hablando de corrupciones textuales, en la misma página, y aunque no se trate de un arabismo, es probable que FAURGA lo sea del precedente fauarega 'habar'.

pág. 298: A propósito de faza y sus muchas variantes, que el autor considera todas reflejos del lat. fascia 'faja', el examen de los contextos parece apoyar a veces la sugerencia de DAAL, pág. 327 de un étimo and. háṣṣa < clásico hișşah 'parte, porción', en casos de grafía fac/ça, mientras que el origen latino parece más probable en fascia, faisca, fascia, faxa, etc., sin perjuicio, claro está, de que haya habido contaminaciones mutuas gráficas y semánticas, incluso de alcance total.

pág. 342: El autor soslaya el posible étimo árabe para gand(a)ra sugerido en DAAL, pág. 310, pese al parecido fonético y semántico, que llega a ser total en asturiano, donde no se trata ya de un terreno estéril, sino incluso pedregoso, seguramente creyendo inverosímil un arabismo en un término descriptivo de la configuración del terreno en zona tan septentrional. No creemos, sin embargo, que esa objeción sea suficiente, a la vista de la penetración de comunidades mozárabes bilingües en todos los rincones del Norte de España, salvo el aún pagano País Vasco, como lo demuestran tantos arabismos del gallego, astur-

en el Kitāb al-Dja\{rafiyyah de Azzuhrī, pág. 252 de la edición de M. Hadj-Sadok, en Bulletin d'Études Orientales (Damasco) XXI, 1968, págs. 7-312, no entendido por el traductor medieval, según Dolors Bramon, El mundo en el siglo XII, Barcelona, Ausa, 1991, pág. 225.

${ }^{8}$ Dictionnnaire arabe-français, Paris, L'Harmattan, 1993-1999, vol. IV, pág. 163. Alguna vez hemos criticado la facilidad con que los lexicógrafos del árabe occidental atribuyen al bereber, por el mero hecho de existir en él, voces a las que no encuentran étimo adecuado, aun siendo a menudo meros préstamos del árabe de etimología menos obvia. Algo parecido sucede con el «prerromano» y las «joyas ibero-vascas» entre los etimólogos del iberorromance.

${ }^{9}$ En su Dictionnaire détaillé des noms des vêtements chez les Arabes, Amsterdam, 1845, páginas 136-138, con las formas ihrām y harim, mientras que la and. ha/irām sólo se halla en su Supplément aux dictionnaires arabes, I, 278, de donde la toma nuestro DAA, pág. 123. 
leonés, aragonés y catalán. Una circunstancia del suelo tan negativa para su valor económico no podía dejar de interesar a aquellos colonos y, por otra parte, la voz ğándal está bien atestiguada en andalusí, desde el Glosario de Leiden, Ibn Quzmān, y el Vocabulista in arabico, hasta el tardío Alcalá, como puede verse en los testimonios de DAA, pág. 105, incluso con un derivado, el participio muğándala 'terreno pedregoso', recogido por dicho Vocabulista.

pág. 343: El autor considera gato como «de origen incierto», al parecer no dando crédito al étimo arameo del lat. cattus $^{10}$, según DAAL, pág. 314 y DAA, pág. 433, pese a la identidad fonética y semántica, y la bien conocida tardía introducción de este animal en Roma, donde en un principio lo sustituía la comadreja (mustela) como erradicadora de roedores. De hecho, cattus es una voz tardía, atribuida a Palladius, en el s. IV después de Cristo, mientras que fele/is, la voz más clásica usada por Cicerón y Varrón, es una clara reutilización de la acepción original 'marta; comadreja', lo que asegura una importación oriental, más bien procedente de Asia Menor que directamente de Egipto, donde se supone tuvo lugar la primera domesticación del primitivo gato, felis libyca.

pág. 404: Creemos que el autor lleva razón al considerar KABIANE como una deturpación de *kabçane en el contexto de «ceramenes kabiane sirguacata», voz esta última que no queda aclarada en pág. 716 y que, en nuestra opinión está también deturpada por *sirgualata, o sea que se trataría de una prenda, la túnica llamada en cast. alhalme (v. DAAL, pág. 49), pero dotada de capucha $^{11}$ y zaragüelles (v. DAAL, pág. 257, s.v. ceroula).

pág. 467: A propósito de maurinus, el autor da moro como de origen incierto, a lo que podemos apostillar que el lat. Mauri puede reflejar el nombre que bien pudo ser dado a los norteafricanos por los fenicios y cartagineses, $<m$ \{rby $>$, literalmente, «occidental» 12 .

pág. 474: El autor considera MESCO como palabra dudosa; sin embargo, esa «cotila de mesco» podría bien ser un bote de almizcle, en los términos de DAAL, pág. 151, s.v. almíscar.

pág. 493: El hápax MOSTELES que aparece en una relación de instrumentos no nos parece ser una horquilla, ni horca, ni guardar relación con la comadreja (mustela), pues apenas se diferencia por una comprensible labialización de un término recogido por el Vocabulista in arabico, el and. miștál, de origen griego, según DAA, pág. 306, y que se ha perpetuado en el andaluz almastrén y

\footnotetext{
${ }^{10}$ Compartido por el and. qattús y el maltés qațtus, que no pueden proceder del latín, mientras que el árabe estándar ha metanalizado y eliminado un sufijo afectivo, y producido la forma qitt.

${ }^{11}$ V. Daal, pág. 70, s.v. alcaceña, para otra utilización del bajo latín capitiana, and. qabṣána.

12 V. Z. Harris, A Grammar of the Phoenician Language, New Haven, American Oriental Society, 1936, pág. 135. El uso del gentilicio <m $\{r b y>$ está bien atestiguado así mismo en ugarítico, v. C.H. Gordon, Ugaritic Textbook, Roma, Pontificium Institutum Biblicum, 1965, pág. 461.
} 
gallego bastrén, de significados algo diversos (v. DAAL, pág. 144), probablemente en el contexto leonés, una llana.

pág. 505: A propósito de nisares y variantes, todos nos habíamos quedado en el étimo bajo latino nixum de Du Cange pero, tratándose de una fruta, muchas de las cuales no se conocieron en Occidente antes de la colonización islámica, hace ya algún tiempo que anotamos a mano en nuestro ejemplar de DAA, págs. 545, que parece tratarse de un reflejo del neopersa nī̌se "variedad de ciruela' ${ }^{13}$.

pág. 658: recelo «cabeza de ganado menor» nos plantea problemas parecidos a los arriba tratados a propósito de haza. El étimo latino del autor puede parecer totalmente convincente, sobre todo en las variantes con $<\mathrm{c}(\mathrm{i})\rangle,\langle\mathrm{z}\rangle$ y $<$ ss $>$, al tiempo que la única con $<\mathrm{x}>$ podría resultar de una contracción gráfica de $\langle$ sc $>$; sin embargo, el hecho de que en portugués, gallego y leonés hayan sobrevivido fundamentalmente formas con $\langle\mathrm{x}\rangle$ parece confirmar el arabismo sugerido en DAAL, pág. 420, totalmente obviado por el autor.

pág. 671: para renzino «algo cojo», que el autor considera derivado de renco y atribuye a un étimo germánico, hubiera tal vez sido pertinente considerar la entrada ronce(ría) en DAAL, pág. 422 y su étimo ár. ramz 'hacer guiños' que parece fonéticamente más próximo y semánticamente apropiado, además de muy apoyado por bastantes voces conexas ${ }^{14}$.

pág. 647: tac/kantes, voz que aparece en casos en que el culpable de un hurto se compromete a resarcir al perjudicado y de la que el autor meramente afirma que no parece una palabra fantasma, parece guardar íntima relación con el también leonés atafeke 'convenio ante tribunal', recogido en DAAL, pág. 203, cuyo étimo ár. and. táfqa podría fácilmente haber simplificado la molesta secuencia /fk/ en los términos allí descritos en pág. xxvii, con algún ejemplo idéntico, vgr., matula, o similar, como mataje y ataquizar.

Finalmente, en pág. 748, tarego «recipiente, vasija», declarado «de etimología incierta», bien podría ser sufijación romance del étimo del cast. tarro, mejor preservado en el galaico-portugués tagra, es decir, el bereber tagra(t), según DAAL, pág. 445, en cuyo caso aquella voz sería esdrújula.

\section{BIBLIOGRAFÍA}

Azzuhr, Kitâb al-Djaçrafiyyah, ed. M. Hadj-Sadok, Bulletin d'Études Orientales, XXI, 1968, págs. 7-312.

13 V. F. J. Steingass, A comprehensive Persian-English dictionary, London (reimp. Beirut 1975), Librairie du Liban, pág. 1442.

${ }^{14}$ Sería un caso más de influencia distorsionadora del prefijo reiterativo romance \{re-\}, v. DAAL, pág. xv, n. 2. 
Bramon, Dolors, El mundo en el siglo XII, Barcelona, Ausa, 1991.

Corriente, Federico, «Los romancismos del Vocabulista in arabico: addenda et corrigenda», Vox Romanica, XXXIX, 1980, págs. 194-210.

Corriente, Federico, «Apostillas etimológicas a las voces orientales del Diccionario de la prosa castellana de Alfonso X de Kasten \& Nitti», Revista de Filología Española, XC, 1, 2010, págs. 47-106.

Corriente, Federico, «Los arabismos de La Lozana Andaluza», Estudis Romànics, XXXII, 2010, págs. 51-72.

Corriente, Federico, «Los arabismos del léxico hispánico primitivo», Revista de Filología Española, LXIV, 1, 2004, págs. 67-93.

Corriente, Federico, A gramatical sketch of the Spanish Arabic dialect bundle, Madrid, Instituto Hispano-Árabe de Cultura, 1977.

Dictionnnaire arabe-français, Paris, L'Harmattan, 1993-1999.

Dozy, Reinhart, Dictionnaire détaillé des noms des vêtements chez les Arabes, Amsterdam, 1845.

Dozy, Reinhart, Supplément aux dictionnaires arabes, Leiden, Brill, 2008.

Gordon, C. H., Ugaritic Textbook, Roma, Pontificium Institutum Biblicum, 1965.

Harris, V. Z., A Grammar of the Phoenician Language, New Haven, American Oriental Society, 1936.

Oliver, Dolores, «Los arabismos en la documentación del Reino de León (siglos IX-XII) y Glosario de arabismos», Orígenes de las lenguas romances en el Reino de León. Siglos IX-XII, II, León, 2004, págs. 99-291.

Oliver, Dolores, A Dictionary of Andalusi Arabic, Leiden, Brill, 1997.

Oliver, Dolores, A Dictionary of Arabic and Allied Loanwords Spanish, Portuguese, Catalan, Galician and Kindred Dialects, Leiden, Brill, 2008.

Simonet, Francisco, Glosario de voces ibéricas y latinas usadas entre los mozárabes, Madrid, Fortanet, 1888.

Steingass, V. F. J., A comprehensive Persian-English dictionary, London, Librairie du Liban, 1975.

Fecha de recepción: 20 de enero de 2011

Fecha de aceptación: 15 de junio de 2011 